\title{
Geopolymer foam as a passive fire protection
}

\author{
Michał Łach $^{1}$, Dariusz Mierzwiński ${ }^{1,{ }^{*}}$, Kinga Korniejenko ${ }^{1}$, Janusz Mikuła $^{1}$ \\ ${ }^{1}$ Cracow University of Technology, Institute of Materials Engineering, Faculty of Mechanical \\ Engineering, 37 Jana Pawła II St., 31-864 Cracow, Poland
}

\begin{abstract}
More than 200 firefighters and 40 fire engines were involved in battling the blaze of Grenfell Tower in June 2017. Despite the heroic efforts of fire brigades the more than 80 people died. In the expert opinion the reason such size of the tragedy were the cladding - installed on in a recent renovation - has come under scrutiny, with experts saying a more fire-resistant type could have been used. The use of such type of cladding was probably price. The main motivation of research work is to develop cheap and fire resistant material for buildings and applications in civil engineering structures. The main aim of the research was development of foamed geopolymers based on fly ash and investigation their properties. The research methods used were: coefficient thermal conductivity test, fire-resistant test, visual analyses, density measurement and compressive strength test. The results show the foamed geopolymers has low coefficient thermal conductivity between 0.068 and $0.126 \mathrm{~W} /(\mathrm{m} \cdot \mathrm{K})$. They have excellent fire and heat resistant facilities, including resistance of this type of materials to the erosive action of fire. Moreover, they have reasonable mechanical properties - they were characterized by compressive strength between 0.5 and $3.5 \mathrm{MPa}$ depending on the density, which ranged from 250 to $700 \mathrm{~kg} / \mathrm{m}^{3}$. The conducted research confirmed that geopolymers have the highest fire resistance classes and can be used on a wide scale as a material for protection against various types of fire and as fire-resistant insulation materials in construction.
\end{abstract}

\section{Introduction}

Up to now, geopolymer materials (GP) have been widely studied as an alternative to cement for structural applications. Only a few studies show their potential as being a thermal insulation material (TIM) [1,2]. After the foaming process, GP can obtain a highly porous structure, high thermal stability, fire resistant and can be produced with the help of cost-effective and safe technology (both for the environment as well as for people). Such unique properties indicate that GPs can be an excellent alternative to conventional TIM $[2,4]$. In fact, conventional TIMs have serious technical limitations as most often they are flammable and their properties decrease as a result of reaching temperatures close to $80^{\circ} \mathrm{C}$, furthermore, they emit toxic gases when exposed to fire, resulting in health risks. Inorganic TIM pose a threat to people (negatively impacting health), and their production process is complex and requires high sintering temperatures.

\footnotetext{
*Corresponding author: dariusz.mierzwinski@mech.pk.edu.pl
} 
The development of TIM systems possessing improved properties is of great importance and will allow us to increase their usability as well as reduce energy consumption in buildings. Despite the obvious suitability of using geopolymer foams as low thermal conductivity materials, this topic was previously omitted in scientific papers.

Alkaline-activated materials and porous geopolymers primarily consist of a geopolymer matrix with a thermal conductivity of 1.0 to $1.2 \mathrm{~W} /(\mathrm{m} \cdot \mathrm{K})$ which is dependent on the type of material being synthesised as well as pores containing dry air which contain a thermal conductivity of $0.026 \mathrm{~W} /(\mathrm{m} \cdot \mathrm{K})$. Considering their light weight, they can be utilised in many industrial as well as construction applications [5]. Porous geopolymers show an increase in compressive strength after being exposed to temperatures of $1000^{\circ} \mathrm{C}$. This is due to an increase in the combination of reaction between polycondensation and sintering at a high temperature. It was concluded that the fire resistance properties of geopolymers are strongly dependent on their chemical composition. One of the important parameters related to the strength of porous geopolymers when subjected to high temperatures is the $\mathrm{Na}_{2} \mathrm{SiO}_{3} / \mathrm{NaOH}$ ratio. The highest possible strength of these materials is obtained at a ratio of 3.5 [6]. Fire resistance improves with the increase in content, e.g. $\mathrm{K}_{2} \mathrm{O}$ [8].

In his research, Davidovits presented the production of a porous geopolymer backbone material by using pore-forming agents such as: hydrogen peroxide $\left(\mathrm{H}_{2} \mathrm{O}_{2}\right)$ or sodium perborate $\left(\mathrm{NaBO}_{3}\right)$ [1]. This research showed that it is possible to produce geopolymer foams with a density between 0.2 and $0.8 \mathrm{~g} / \mathrm{cm}^{3}$, with an apparent thermal resistance of up to $1200^{\circ} \mathrm{C}$ and a minimum thermal conductivity of $0.037 \mathrm{~W} /(\mathrm{m} \cdot \mathrm{K})$. Vaou and Panias [7] managed to reduce the thermal conductivity coefficient to $0.030 \mathrm{~W} /(\mathrm{m} \cdot \mathrm{K})$ by using perlite.

A good dependence of the heat conduction coefficient on the density of the produced materials was found. In order to improve (lower) the thermal conductivity coefficient, it would be necessary to reduce the material density (increase the degree of foaming) by increasing the amount of foaming agent [4].

Thus far, the geopolymers that foamed most often were produced on the basis of fly ash, but it is also possible to produce foamed insulating geopolymer composites based on metakaolinite and biomass ash [5].

\section{Experiments}

\subsection{Materials}

To produce geopolymers used technical sodium hydroxide flakes and an aqueous sodium silicate solution of R-145 module 2.5 and a molar density of about $1.45 \mathrm{~g} / \mathrm{cm}^{3}$. The mixture was not used distilled water. The alkaline solution was prepared in this way that the solid sodium hydroxide was poured over an aqueous solution of sodium silicate and water. The solution was thoroughly mixed and allowed to equilibrate until a constant concentration and temperature.

The study used fly ashes from power plant in Skawina. The composition of the oxide and the physical and chemical properties are shown in table 1. Microspheres (Mikromex) as well as $35 \%$ hydrogen peroxide (Chempur) were also used for the production of geopolymer foams. The microspheres had a particle size of $100 \div 500 \mu \mathrm{m}$.

Table 1. Oxide content in fly ash.

\begin{tabular}{|c|c|c|c|c|c|c|c|c|c|c|c|}
\hline Oxide & $\mathbf{S i O}_{\mathbf{2}}$ & $\mathbf{A l}_{\mathbf{2}} \mathbf{O}_{\mathbf{3}}$ & $\mathbf{F e}_{\mathbf{2}} \mathbf{O}_{\mathbf{3}}$ & $\mathbf{C a O}$ & $\mathbf{M g O}$ & $\mathbf{N a}_{\mathbf{2}} \mathbf{O}$ & $\mathbf{K}_{\mathbf{2}} \mathbf{O}$ & $\mathbf{S O}_{\mathbf{3}}$ & $\mathbf{T i O}_{\mathbf{2}}$ & $\mathbf{P}_{\mathbf{2}} \mathbf{O}_{\mathbf{5}}$ & $\mathbf{B a O}$ \\
\hline $\begin{array}{c}\text { Content } \\
{[\%]}\end{array}$ & 55.89 & 23.49 & 5.92 & 2.72 & 2.61 & 0.59 & 3.55 & 0.16 & 1.09 & 0.82 & 0.20 \\
\hline
\end{tabular}


The geopolymer foams were prepared in such a way that solid constituents such as fly ash, microspheres and sand were mixed until reaching a homogeneous state, then an alkaline solution - $6 \mathrm{M}$ sodium hydroxide solution with the addition of sodium silicate in the ratio 1:2.5, was introduced. The material was mixed for $10 \mathrm{~min}$. An appropriate amount of hydrogen peroxide was then introduced and continuously mixing for approx. $1 \mathrm{~min}$. After the mixing process was complete, the material was poured into a mould and exposed to a temperature of $75^{\circ} \mathrm{C}$ for a period of 24 hours. After the heating process, the element was dismantled and stored under laboratory conditions for a period of 28 days in order to obtain full strength.

\subsection{Examination methods}

The morphology of samples was studied with a JEOL JSM-820 scanning microscope. Samples were appropriately prepared beforehand. Small quantities of materials were dried to constant mass, and next they were placed on a carbon substrate that ensures removing the charge from the sample. The materials were coated with a thin layer of gold by a JEOL JEE-4X Vacuum Evaporator.

The thermal conductivity coefficient was calculated in accordance with the PN-EN 12667:2002. The measurements were carried out under the steady-state conditions of heat transfer, at the average sample temperature amounting to $10^{\circ} \mathrm{C}$, for the samples whose dimensions were $300 \times 300 \times 100 \mathrm{~mm}$. The applied temperature difference was $20^{\circ} \mathrm{C}$ for the thickness of the sample $\left(\mathrm{T}_{1}=0^{\circ} \mathrm{C}, \mathrm{T}_{2}=20^{\circ} \mathrm{C}, \mathrm{T}_{\text {mean }}=10^{\circ} \mathrm{C}\right)$. The tests were conducted in the closed test chamber (having thermally-insulated walls) in the one-sample plate apparatus HFM 436/3/0, NETZSCH provided with the heat-flow density sensor. The results were compared with the certified reference values IRMM-440 no 30. The bulk density of the product was calculated as a ratio of the mass to the volume of the sample, without referring to the certified specimen.

\section{Results}

Table 2 presents the test results of the composition of foamed geopolymers. The lowest thermal conductivity value of $0.068 \mathrm{~W} /(\mathrm{m} \cdot \mathrm{K})$ was obtained from material containing $50 \%$ spheres and $5 \% \mathrm{H}_{2} \mathrm{O}_{2}$. Simultaneously, this material was characterised by the lowest density and the lowest value of compressive strength amounting to $0.43 \mathrm{MPa}$. The highest density, compressive strength and thermal conductivity value were obtained from the composition [7] containing $10 \%$ microspheres and $2 \% \mathrm{H}_{2} \mathrm{O}_{2}$.

Table 2. Composition and physical properties of geopolymer foams.

\begin{tabular}{|c|c|c|c|c|}
\hline Sample labels & $\begin{array}{c}\text { Composition, additives } \\
{[\% \text { obj.] }}\end{array}$ & $\begin{array}{c}\text { Density } \\
{\left[\mathbf{k g} / \mathbf{m}^{\mathbf{3}}\right]}\end{array}$ & $\begin{array}{c}\text { Heat conductivity } \\
{[\mathbf{W} / \mathbf{m} \cdot \mathbf{K}]}\end{array}$ & $\begin{array}{c}\text { Compressive } \\
\text { strength [MPa] }\end{array}$ \\
\hline GEO1 & $\begin{array}{c}20 \% \text { microspheres; } 6 \% \\
\mathrm{H}_{2} \mathrm{O}_{2} ; 3 \% \text { perlite }\end{array}$ & 311.2 & 0.07986 & 1.12 \\
\hline GEO2 & $\begin{array}{c}30 \% \text { microspheres; } 5 \% \\
\mathrm{H}_{2} \mathrm{O}_{2} ;[7]\end{array}$ & 414.07 & 0.0980 & 1.90 \\
\hline GEO3 & $\begin{array}{c}10 \% \text { microspheres; } 2 \% \\
\mathrm{H}_{2} \mathrm{O}_{2} ;[7]\end{array}$ & 640.46 & 0.1273 & 3.4 \\
\hline GEO4 & $\begin{array}{c}50 \% \text { microspheres; } 5 \% \\
\mathrm{H}_{2} \mathrm{O}_{2} ;\end{array}$ & 251.65 & 0.068 & 0.43 \\
\hline
\end{tabular}


Figure 1 presents the exemplary structure of foamed geopolymer. The diagram shows the pores and microspheres, which were added to the geopolymer mixture during manufacture.

Figure 2 illustrates the appearance of the chambers in which the tests were carried along with the placement of the test samples. The gas used was propane.

The tests were conducted in conditions similar to those defined in the mini jet-fire tests. This being a smaller scale test configuration developed mainly for the purpose of preliminary testing of materials. The mini nozzle uses a pre-mixed flame consisting of air and propane in order to obtain a similar temperature as in the case of a standard jet fire, in accordance with ISO 22899-1. The temperature of the flame is similar, the effect of erosion on the sample is however not comparable.

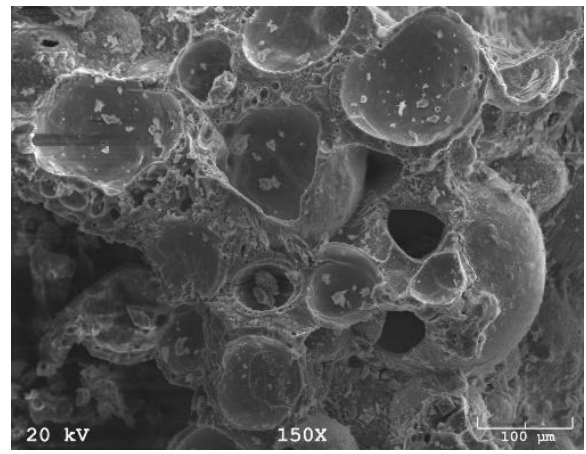

Fig. 1. Structure of foamed geopolymer.
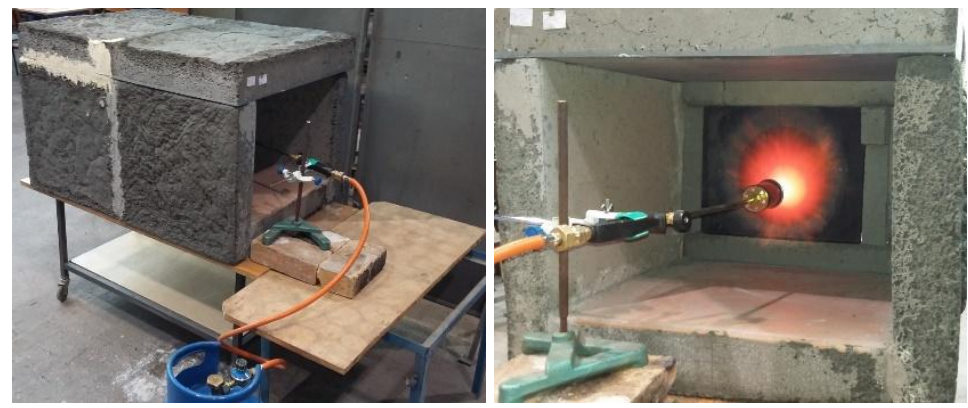

Fig. 2. The fire chamber, before closing the entrance to the hot section.
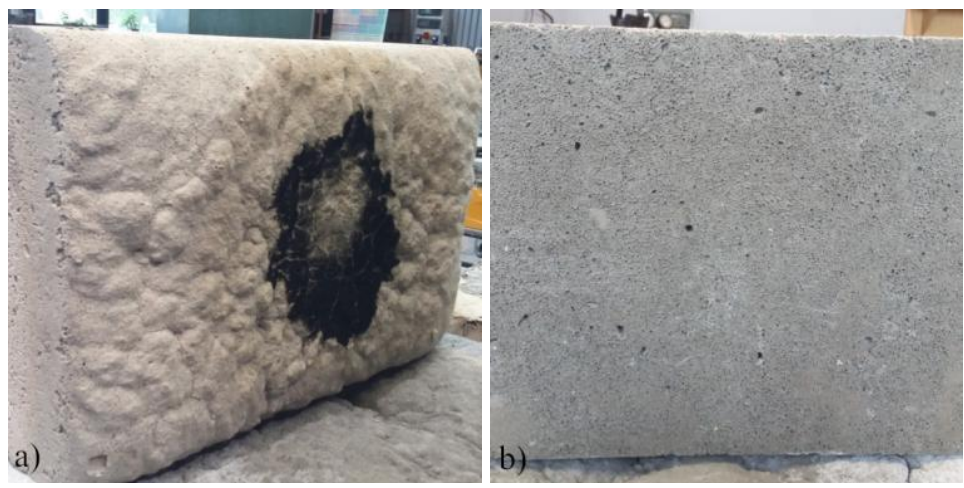

Fig. 3. The board surface with a thickness of $100 \mathrm{~mm}$ from the hot section, after fire resistance testing (a) and from the cold section, after resistance testing (b). 
Figures 4 and 5 present the results of fire resistance tests carried out in the firebox for boards made of GEO1 material with a thickness of $45 \mathrm{~mm}$ and $100 \mathrm{~mm}$. The temperature distribution is presented as a function of the heating time for the tested surfaces from the side of the heating flame and from the side located in the "cold" chamber.

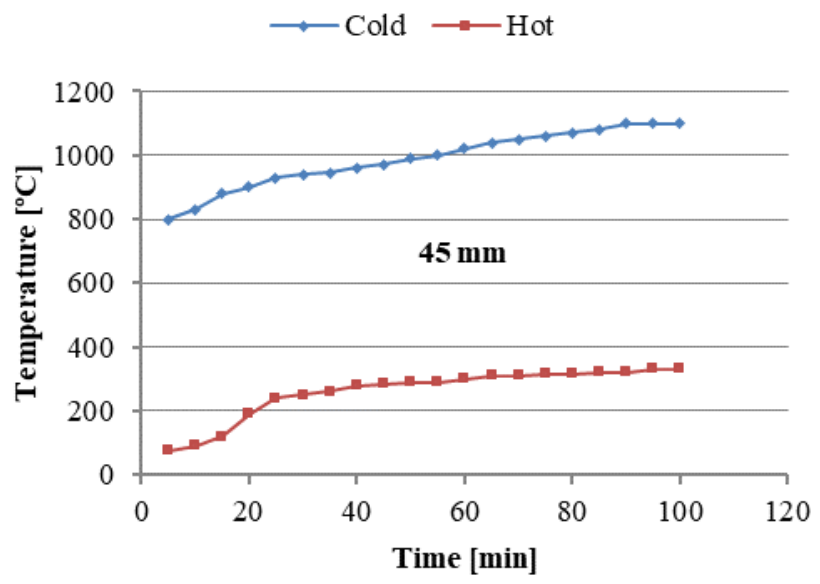

Fig. 4. Fire resistance test results for a $45 \mathrm{~mm}$ thick board.

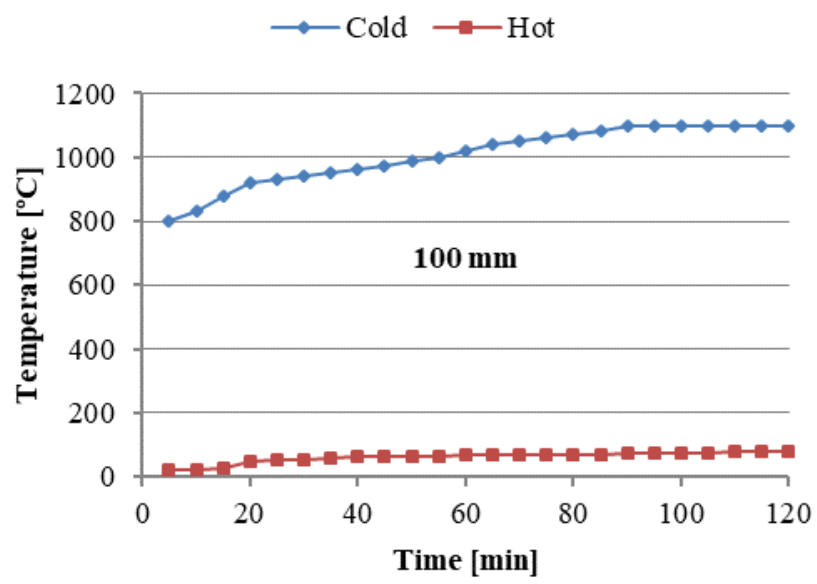

Fig. 5. Fire resistance test results for a $100 \mathrm{~mm}$ thick board.

\section{Conclusion}

Foamed geopolymers and geopolymer composites create an attractive material which can be utilised in fire protection covers. The examined geopolymers, in the form of foamed boards with a thickness of $100 \mathrm{~mm}$, showed considerable resistance to the erosive effect of fire and were characterised by a high degree of insulation. After more than 2 hours of being heated in the chamber and reaching a surface temperature of $1100^{\circ} \mathrm{C}$, the temperature on the other side of the board did not exceed $100^{\circ} \mathrm{C}$. 


\section{References}

1. J. Davidovits, Geopolymer: Chemistry and Applications 4 (2015)

2. L. Provis, J.S.J. van Deventer, Geopolymers: structure, processing, properties and industrial applications, 1 (2009)

3. H. Xu, J. Van Deventer, Int. J. Miner. Process. 59, 3 (2000)

4. M. al B.A. Mohd, J. Liyana, H. Kamarudin, B. Mohamed, M.R.G. Che, I.A. Mohd, Int J. Mol. Sci. 13, 4 (2012)

5. V. Vaou, D. Panias, Miner. Eng. 23, 14 (2010)

6. T.W. Cheng, J.P. Chiu, Miner. Eng. 16, 3 (2003)

7. M. Łach, K. Korniejenko, J. Mikuła, Procedia Eng. 151, 410-416 (2016)

8. A.N. Murri, V. Medri, E. Papa, L. Laghi, C. Mingazzini, E. Landi, Environments 4, 4 (2017) 